\title{
Trabeculectomy with intraoperative sponge 5-fluorouracil in Afro-Caribbeans
}

\author{
Yves Lachkar, Martin Leyland, Philip Bloom, Clive Migdal
}

\begin{abstract}
Aim-To study the efficacy and safety of intraoperative 5-fluorouracil (5-FU) in Afro-Caribbean patients.

Methods-The results of trabeculectomy in 18 eyes of 18 Afro-Caribbean patients in whom a sponge soaked in $25 \mathrm{mg} / \mathrm{ml}$ solution of 5-FU was applied between Tenon's capsule and sclera for 5 minutes before excision of the trabecula were compared with 16 eyes of 16 Afro-Caribbean patients matched for age, quantity, and duration of preoperative medications, who underwent trabeculectomy without 5-FU. Results-The mean postoperative intraocular pressure (IOP) at 1 month was 15.6 (SD 6.1) $\mathrm{mm} \mathrm{Hg}$ in the 5-FU group and 18.0 (5.2) $\mathrm{mm} \mathrm{Hg}$ in the control group $(p=0.15)$. There was no significant difference in the IOP at $6,12,15,18$, and 24 months in the two groups. Success rate at 18 months defined as an IOP less than or equal to $21 \mathrm{~mm} \mathrm{Hg}$ with no adjunctive medication was $56 \%$ in the $5-F U$ group and $55 \%$ in the control group. No major complications were noted in either group. Conclusion-Intraoperative sponge 5-FU alone is safe but does not appear to decrease the risk of failure of trabeculectomy in Afro-Caribbeans.

(Br f Ophthalmol 1997;81:555-558)
\end{abstract}

Previous studies have reported poor success rates after routine filtration operations in AfroCaribbean patients particularly if they are young. ${ }^{1-5}$

The use of postoperative subconjunctival 5-fluorouracil (5-FU) has considerably improved the success rate of glaucoma filtering surgery. However, because this antimetabolite may cause corneal epithelial defects in the early postoperative period and because of the inconvenience of repeated subconjunctival injections, the use of intraoperative sponge 5-FU has been proposed. ${ }^{6-10}$ Other antimetabolites have also been tried, including mitomycin C. ${ }^{11}$ Late bleb leakage, infection, and severe hypotony have been reported with this drug ${ }^{12}$ with documented irreversible maculopathy. ${ }^{13}$ This has led to re-evaluation of the use of 5-FU.

To assess the efficacy and safety of $5-\mathrm{FU}$ applied at the time of trabeculectomy in AfroCaribbean patients without other risk factors for failure, we analysed the results in 18 consecutive operations in which this technique was used. The surgical results were compared with those in a matched control group of 16 eyes who underwent trabeculectomy without 5-FU.

Material and methods

From 1992 to 1995, trabeculectomy was performed with adjunctive 5-FU application in 18 eyes of 18 consecutive Afro-Caribbean patients. Informed consent was obtained from all patients. A control group of 16 eyes of 16 Afro-Caribbean patients who had undergone trabeculectomy for glaucoma without antimetabolite therapy was identified retrospectively. Exclusion criteria for both groups were: traumatic glaucoma; patient age of 30 years or younger; previous surgery to the conjunctiva including trabeculectomy, aphakia, pseudophakia, uveitic glaucoma, previous argon laser trabeculoplasty in the past 6 months; and neovascular glaucoma.

In those patients receiving intraoperative 5-FU the conjunctival flap was limbus based in 16 cases and fornix based in two cases. In the control group the conjunctival flap was limbus based in 12 cases and fornix based in four cases. After haemostasis of the episclera was attained, 5-FU was applied between sclera and Tenon's capsule for 5 minutes with a surgical sponge that measured approximately $4.5 \times 4.5$ $\mathrm{mm}$ and that had been previously soaked in a $25 \mathrm{mg} / \mathrm{ml}$ solution of 5-FU (David Bull Laboratories, Warwick).

After 5 minutes the sponge was removed and the entire area was thoroughly irrigated with 40 $\mathrm{ml}$ balanced saline solution. A $4.0 \times 4.0 \mathrm{~mm}$ limbus based scleral flap was dissected into clear cornea. A $1.00 \times 2.00 \mathrm{~mm}$ deep scleral block was removed and a peripheral iridectomy was performed. The scleral flap was closed by two interrupted 10-0 nylon sutures. Tenon's capsule and the conjunctival layer were sutured by using a continuous $8-0$ Vicryl suture on a round bodied needle for limbus based flaps. In patients where a fornix based conjunctival flap was used the conjunctiva was closed with interrupted 8-0 Vicryl sutures. Subconjunctival injection of $20 \mathrm{mg}$ cefuroxime and $1.5 \mathrm{mg}$ betamethasone acetate was administered in the inferior fornix. Postoperatively, topical chloramphenicol was used four times daily for 4 postoperative weeks and topical prednisolone $1 \%$ or dexamethasone $0.1 \%$ was used four to six times a day for 2 months and progressively tapered over an additional month.

Patients were examined 1,7 , and 15 days postoperatively and then $1,3,6,9,12,15,18$, and 24 months postoperatively. At each postoperative visit patients were fully examined
Accepted for publication 26 March 1997 
Table 1 Patient characteristics in two groups of patients who received trabeculectomy with or without intraoperative 5-FU

\begin{tabular}{llll}
\hline & $\begin{array}{l}\text { Trabeculectomy with } \\
5-F U(n=18)\end{array}$ & $\begin{array}{l}\text { Control group } \\
(n=16)\end{array}$ & $p$ Value \\
\hline Age (years): & $50.5(16.1)$ & $55.8(15.1)$ & 0.37 \\
$\quad$ Mean (SD) & $30-70$ & $38-68$ & \\
$\quad$ Range & $8(45 \%)$ & $6(38 \%)$ & \\
Sex: & $10(55 \%)$ & $10(62 \%)$ & \\
$\quad$ Female & $17.4(4.8)$ & $23.5(1.6)$ & \\
$\quad$ Male & $12-24$ & $12-24$ & \\
Follow up (months) & & & \\
$\quad$ Mean (SD) & $24.9(4.1)$ & $24.0(3.0)$ & 0.56 \\
$\quad$ Range & $18-29$ & $18-28$ & \\
Preoperative IOP (mm Hg) & $1.57(0.51)$ & $1.82(0.26)$ & 0.2 \\
$\quad$ Mean (SD) & $3.66(3.05)$ & $4.26(3.52)$ & 0.35 \\
$\quad$ Range & & & \\
Number of medications (SD) & & \\
Duration of medications (years) (SD) & & \\
\hline
\end{tabular}

Table 2 Comparison of preoperative and postoperative mean (SD) intraocular pressure $(\mathrm{mm} \mathrm{Hg})$ in 5-FU or control group

\begin{tabular}{llll}
\hline & $\begin{array}{l}\text { Trabeculectomy } \\
\text { with 5-FU } \\
(n=18)\end{array}$ & Control group & p Value \\
\hline Preop value & $24.9(4.1)$ & $24.0(3.0)$ & 0.56 \\
1 month & $15.6(6.1)$ & $18.1(5.2)$ & 0.15 \\
3 months & $19.2(6.1)$ & $18.6(5.7)$ & 0.84 \\
6 months & $17.9(6.3)$ & $18.0(1.6)$ & 0.93 \\
12 months & $17.0(6.5)$ & $19.2(4.3)$ & 0.46 \\
15 months & $20.3(4.3)$ & $18.0(3.4)$ & 0.74 \\
18 months & $16.9(3.0)$ & $19.5(4.5)$ & 0.37 \\
24 months & $17.2(2.9)$ & $17.0(4.1)$ & 0.95 \\
\hline
\end{tabular}

at the slit-lamp and the visual acuity, intraocular pressure (Goldmann applanation tonometry), slit-lamp biomicroscopy (bleb appearance), and fundal examination were determined. Results were documented retrospectively.

The operation was considered a success when the intraocular pressure was less than or equal to $21 \mathrm{~mm} \mathrm{Hg}$ off all glaucoma medication and a failure when the intraocular pressure was greater than $21 \mathrm{~mm} \mathrm{Hg}$ with or without glaucoma medication.

Comparisons between the two groups were performed by using comparison of means in paired samples and $\chi^{2}$ analysis for $2 \times 2$ tables. Kaplan-Meier survival curves were drawn with success rate estimates at 3 month intervals. A finding was considered significant if the $\mathrm{p}$ value was less than 0.05. Comparison between the 5-FU treated group and the control group was performed using the log rank test.

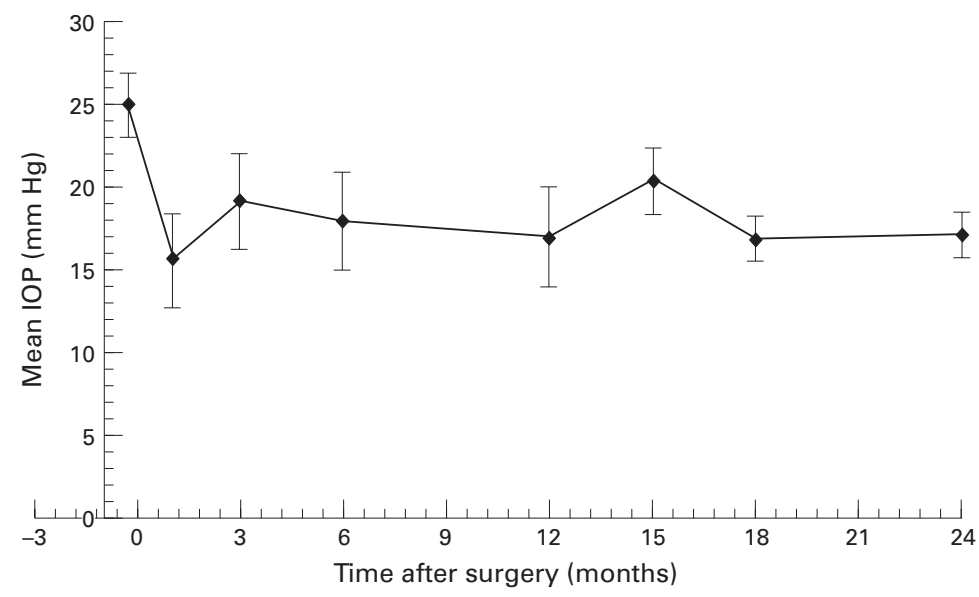

Figure 1 Evolution of intraocular pressure in the 5-FU group.
Table 3 Surgical complications in the two groups

\begin{tabular}{lll}
\hline & $\begin{array}{l}\text { Trabeculectomy } \\
\text { with 5-FU } \\
(n=18)\end{array}$ & $\begin{array}{l}\text { Control group } \\
(n=16)\end{array}$ \\
\hline Cystic/thin bleb & 6 & 3 \\
Wound leak & 1 & 0 \\
Punctate keratopathy & 1 & 1 \\
Choroidal detachment & 0 & 0 \\
Shallow anterior chamber & 1 & 0 \\
Hypotony & 0 & 0 \\
Cataract & 0 & 0 \\
Endophthalmitis & 0 & 0 \\
Drug addition & 8 & 7 \\
Repeat surgery & 2 & 1 \\
\hline
\end{tabular}

\section{Results}

Table 1 lists the patient characteristics, follow up, and preoperative intraocular pressures. The trial and control group were well matched with no statistical difference between the two groups for age, preoperative intraocular pressure, number of topical medications, and cumulative duration of medications used.

Table 2 lists the intraocular pressure outcome. The intraocular pressure reduction was greater in the 5-FU group at the first month but the difference was not statistically significant. Evolution of intraocular pressure in the two groups is presented in Figures 1, 2, and 3.

The Kaplan-Meier survival curve for trabeculectomy with intraoperative sponge $5-\mathrm{FU}$ is shown in Figure 4. The difference, using the $\log$ rank test is not statistically significant.

The complications encountered in this series are listed in Table 3

In the control group seven patients (43\%) required additional medical therapy; four patients required one drug ( $\beta$ blocker), and three patients required two drugs ( $\beta$ blocker + pilocarpine). Four of these seven patients received two 5-FU injections $(5 \mathrm{mg})$ at the end of the second month, as an attempted treatment for bleb failure. One patient had a second trabeculectomy with antimetabolite (mitomycin C) 8 months after the first trabeculectomy. These four patients were considered as early failures. In the 5-FU group two patients required a second trabeculectomy (with mitomycin $\mathrm{C}$ ), the first one at 3 months and the second at 6 months after the initial trabeculectomy. Eight patients $(44 \%)$ in total required additional therapy medical or surgical.

\section{Discussion}

Antimetabolites are used to reduce risk of surgical failure from postoperative scarring of the trabeculectomy bleb. Poor success rates after routine filtration operations in black patients have been reported suggesting the need for antimetabolites. ${ }^{14}$ The use of postoperative subconjunctival injection of 5-FU or intraoperative application of mitomycin $\mathrm{C}$ has considerably improved the success rate of the glaucoma filtering procedure. ${ }^{15}{ }^{16}$ However, the use of a single 5 minute application of $5-\mathrm{FU}$ during glaucoma filtration surgery has been proposed to avoid the serious complications seen with mitomycin ${ }^{12} 13$ and avoiding the need to administer repeated subconjunctival injections in accordance with the original protocols for the use of 5 -FU. ${ }^{15}$ 


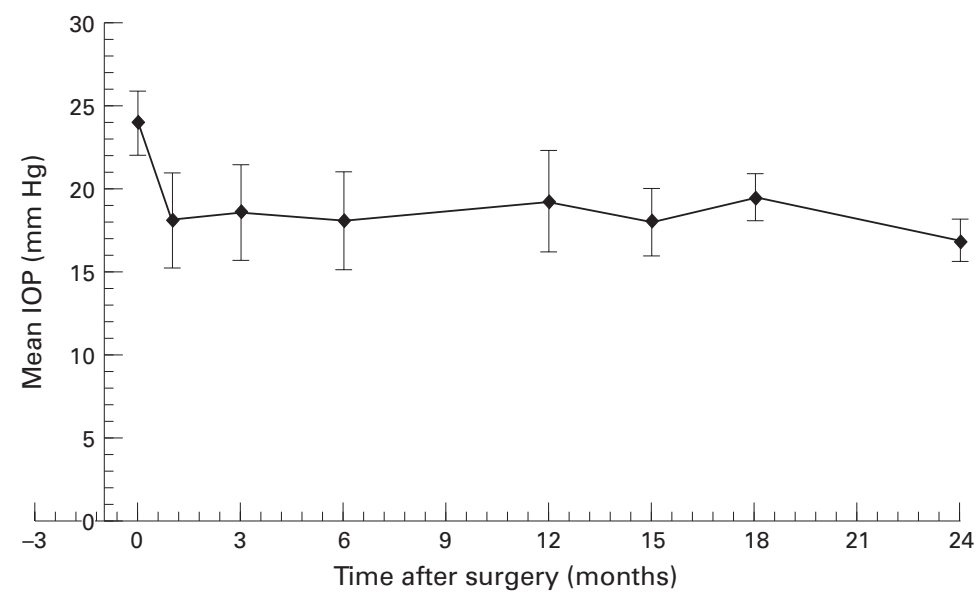

Figure 2 Evolution of intraocular pressure in the control group.

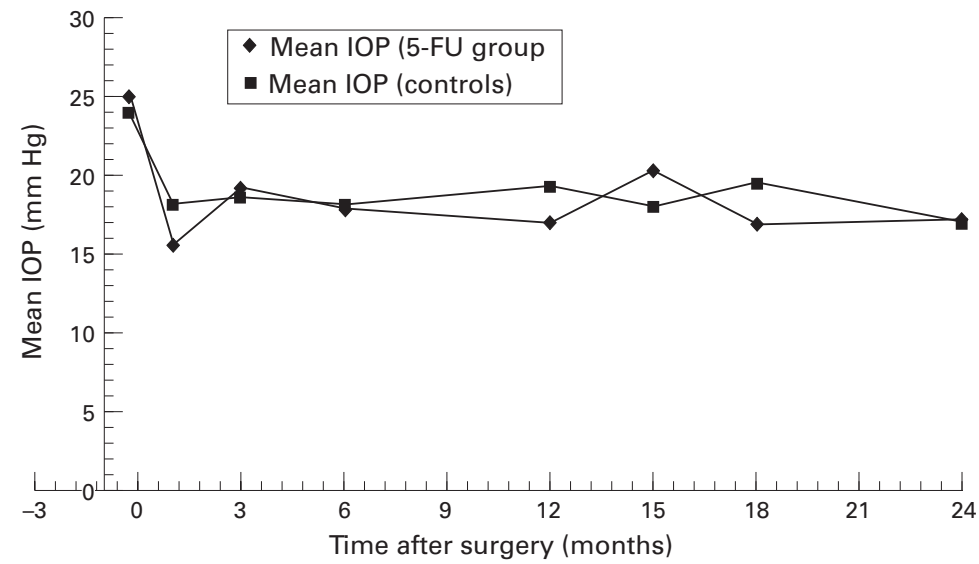

Figure 3 Comparison of the intraocular pressure evolution between the 5-FU and the control group. sclera and subconjunctival tissues to $5-\mathrm{FU}$ (25 $\mathrm{mg} / \mathrm{ml}$ ) showed good results but the follow up period was limited ( 3 to 9 months). ${ }^{8}$

Feldman $e t a l^{9}$ reported a 6 month prospective series of 43 cases with intraoperative 5-FU including eight black patients. Seven patients were treated successfully but adjunctive medication treatment was permissible.

More recently, in a study of trabeculectomy with intraoperative sponge $5-\mathrm{FU},{ }^{10} 105$ of 140 eyes required supplementary injections of 5-FU with a mean number of injections of 5.3 (SD 2.7) (range 1-14). For low risk eyes (eyes without risk factors except for previous topical medications) the mean number of injections was 4.8 (2.4), and for high risk eyes the mean number was 5.7 (3.2) injections.

A Ghanian series ${ }^{19}$ of 55 eyes with a mean follow up of 282 days randomly selected to receive or not receive a single application of 5 -FU ( $50 \mathrm{mg} / \mathrm{ml} 5$ minutes) without use of postoperative injections concluded that intraoperative 5-FU improved the ability of trabeculectomy to lower intraocular pressure in a black African population. The number of eyes with previous operations was not statistically different in the two groups but the use and the number of preoperative medications was not mentioned.

We used a concentration of $25 \mathrm{mg} / \mathrm{ml}$ of 5-FU based on laboratory studies. ${ }^{20}$ This is the highest concentration commercially available in the UK.

Laboratory studies suggest that a 5 minute 5-FU exposure should be effective in inhibiting the proliferation of ocular fibroblasts. ${ }^{20-23}$

In a masked randomised prospective study in a rabbit model $^{21}$ a single intraoperative exposure to $5-\mathrm{FU}(50 \mathrm{mg} / \mathrm{ml}$ concentration for 5 minutes) resulted in consistently higher blebs than a placebo (distilled water). However, in the same study it was shown that a combination of intraoperative and postoperative 5-FU (five injections on postoperative days $1,3,5,7$ ) produced significantly higher blebs than intraoperative 5-FU alone.

Khaw et $a l^{20}$ compared the effect of a single application of mitomycin $(0.4 \mathrm{mg} / \mathrm{ml})$ and 5-FU $(50 \mathrm{mg} / \mathrm{ml})$, demonstrating that 5 minute intraoperative treatments with 5 -FU resulted in a reversible delay of fibroblast outgrowth from treated subconjunctival and scleral tissues of just over 1 week in an animal model (white albino rabbit), whereas treatment

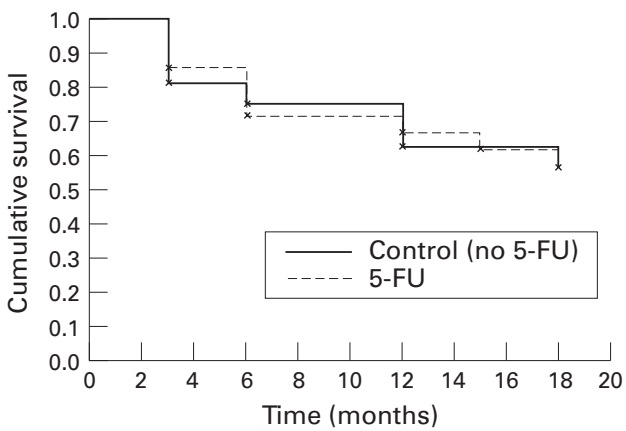

Figure 4 Kaplan-Meier analysis of the probability of IOP survival $<22 \mathrm{~mm} \mathrm{Hg}$. 
Table 4 Previously success rates of trabeculectomy surgery in Afro-Caribbean patients

\begin{tabular}{|c|c|c|c|c|c|c|}
\hline Authors & $N$ & Antimetabolite & Follow up & Success criteria & $\%$ Success & Comment \\
\hline Freedman ${ }^{3}$ & 51 & No & 19 months & IOP $<20$ without med & 57 & \\
\hline David $^{4}$ & 19 & No & $\begin{array}{l}\text { 6-30 } \\
\text { months }\end{array}$ & $\begin{array}{l}\text { IOP }<20 \text { with or without } \\
\text { med }\end{array}$ & 73.6 & $\begin{array}{l}16(63 \%) \text { patients with add } \\
\text { treatment }\end{array}$ \\
\hline Thommy $^{26}$ & 139 & No & 6 months & IOP $<20$ without med & 95 & \\
\hline Wilson ${ }^{27}$ & 32 & No & 28 months & IOP $<20$ without med & 53 & \\
\hline \multirow[t]{2}{*}{ Mermoud $^{28}$} & 30 & No & 9 months & IOP $<20$ without med & 37 & other risk factors included \\
\hline & 30 & $\begin{array}{l}\text { Mitomycin }(0.2 \\
\mathrm{mg} / \mathrm{ml})\end{array}$ & 9 months & IOP $<20$ without med & 83 & \\
\hline \multirow[t]{2}{*}{ Egbert $^{19}$} & 31 & No & 282 days & IOP $<20$ without med & 32 & previous surgery included \\
\hline & 24 & $5-\mathrm{FU}(50 \mathrm{mg} / \mathrm{ml})$ & 282 days & IOP $<20$ without med & 71 & intraoperative 5 -FU \\
\hline \multirow{3}{*}{$\begin{array}{l}\text { Current } \\
\text { study }\end{array}$} & & & & & & \\
\hline & 16 & No & 18 months & IOP $<22$ without med & 55 & \\
\hline & 18 & $5-\mathrm{FU}(25 \mathrm{mg} / \mathrm{ml})$ & 18 months & IOP $<22$ without med & 56 & \\
\hline
\end{tabular}

$\mathrm{N}=$ number of eyes.

with mitomycin C $0.4 \mathrm{mg} / \mathrm{ml}$, resulted in prolonged inhibition for at least 30 days.

The same authors also showed ${ }^{24}$ that in rabbits intraoperative sponge 5-FU significantly increases bleb survival, though not to the same extent as does mitomycin C. At 30 days after surgery, blebs were present in $100 \%$ of eyes treated with mitomycin C $0.4 \mathrm{mg} / \mathrm{ml}, 60 \%$ of eyes treated with $0.2 \mathrm{mg} / \mathrm{ml}$, and $0 \%$ of eyes treated with distilled water or a single 5 minute application intraoperative exposure to $5-\mathrm{FU}$ (50 $\mathrm{mg} / \mathrm{ml}$ ).

In our study no major complications were noted. Sponge application of 5-FU did not appear to cause corneal epithelial toxicity. However, we were not able to demonstrate that a single intraoperative application of 5-FU enhanced the success rate of trabeculectomy in the Afro-Caribbean population. Our success rate is lower than in primary trabeculectomy without antimetabolite ${ }^{25}$ but comparable with other studies of black populations (Table 4).

\section{Conclusion}

Although this study reported two groups with a small number of patients our results suggest that in Afro-Caribbeans patients the success rate of trabeculectomy is not enhanced by a single intraoperative application of 5-FU. It may be that additional postoperative 5-FU injections are required to achieve satisfactory results in this group of patients. A prospective study comparing intraoperative sponge $5-\mathrm{FU}$ combined with additional postoperative subconjunctival injections with intraoperative mitomycin $\mathrm{C}$ would be helpful to assess the role of a higher level of antifibrosis suppression in this group of patients

The authors have no proprietary interest in any of the materials used in this study.

Presented at the United Kingdom and Eire Glaucoma Presented at the United Kingdo
Society, London, November 1996.

1 Berson D, Zauberman H, Landau L, Blumenthal M. Filtering operations in Africans. Am f Ophthalmol 1969;67:395ing.

2 Welsch NH. Trabeculectomy with fistula formation in the African. Br f Ophthalmol 1972;56:32-5.

3 Freedman J, Shen E, Ahrens M. Trabeculectomy in a black American population. $\mathrm{Br} \mathcal{F}$ Ophthalmol 1976;60:573-4.

4 David R, Freedman J, Luntz MH. Comparative study of Watson's and Cairns' trabeculectomies in a black population with open angle glaucoma. $\operatorname{Br} \mathcal{F}$ Ophthalmol 1977;61: $117-9$ 5 Merrit JC. Filtering procedures in American blacks.
Ophthalmic Surg 1980;11:91-5.
6 Dietze PJ, Feldman RM, Gross RL. Intraoperative applications of 5-fluorouracil during trabeculectomy. Ophthalmic Surg 1992;23:662-5

7 Smith MF, Sherwood MB, Doyle JW, Khaw PT. Results of intraoperative 5-fluorouracil supplementation on trabeculectomy for open-angle glaucoma. Am $\mathcal{f}$ Ophthalmol 1992;114:737-41.

8 Lanigan L, Sturmer J, Baez KA, Hitchings RA, Khaw PT. Single intraoperative applications of 5-fluorouracil during filtration surgery: early results. $\mathrm{Br} \mathcal{F}$ Ophthalmol 1994;78: filtration.

9 Feldman RM, Dietze PJ, Gross RL, Oram O. Intraoperative 5 fluorouracil administration in trabeculectomy. $\mathcal{f}$ Glaucoma 1994;3:302-7.

10 Mora JS, Nguyen N, Iwach AG, Gaffney M, Hetherington J $\mathrm{Jr}$, Hoskins HD Jr, et al. Trabeculectomy with intraoperative sponge 5 fluorouracil. Ophthalmology 1996;103:96370 .

11 Kitazawa Y, Kawase K, Matsushita H, Minobe M. Trabeculectomy with mitomycin. A comparative study with fluorouracil. Arch Ophthalmol 1991;109:1693-8.

12 Zacharia PT, Deppermann SR, Schuman JS. Ocular hypotony after trabeculectomy with mitomycin C. Am f Ophthalmol 1993;116:314-26.

13 Jampel HD, Pasquale LR, Dibernardo C. Hypotony maculopathy following trabeculectomy with mitomycin C. Arch Ophthalmol 1992;110:1049-53.

14 Parrish RK. Who should receive antimetabolites after filtering surgery? Arch Ophthalmol 1992;11:1069-71.

15 The Fluorouracil Filtering Surgery Study Group. Fluorouracil filtering surgery study one-year follow-up. $\mathrm{Am} f$ Ophthalmol 1989;108:625-35.

16 Fluorouracil Filtering Surgery Study Group. Three-year follow-up of the fluorouracil filtering surgery study. $A m \mathcal{F}$ Ophthalmol 1993;115:82-92.

17 Fluorouracil Filtering Surgery Study Group. Five-year follow-up of the fluorouracil filtering surgery study. $A m \mathcal{F}$ Ophthalmol 1996;121:349-66.

18 Parrish RK. The importance of fibrosis inhibition in high risk glaucoma surgery. Curr Opin Ophthalmol 1993;4(II): 93-7.

19 Egbert PR, Williams AS, Singh F, Dadzie P, Egbert TB. A prospective trial of intraoperative fluorouracil during trabeculectomy in a black population. Am $\mathcal{f}$ Ophthalmol 1993;116:612-6.

20 Khaw PT, Doyle JW, Sherwood MB, Grierson I, Schultz G, McGorray S. Prolonged localized tissue effects from 5-minute exposures to fluorouracil and mitomycin C. Arch Ophthalmol 1993;111:263-7.

21 Doyle JW, Sherwood MB, Khaw PT, McGrory S, Smith MF. Intraoperative 5-fluorouracil for filtration surgery in $M F$. Intraoperative 5-fluorouracil for filtration surger
the rabbit. Invest Ophthalmol Vis Sci 1993;34:3313-9.

22 Khaw PT, Sherwood MB, MacKay SL, Rossi MJ, Schultz G. Five-minute treatments with fluorouracil, fluoxuridine, and mitomycin have long-term effects on human Tenon's capsule fibroblasts. Arch Ophthalmol 1992;110:1150-4.

23 Khaw PT, Ward S, Porter A, Grierson I, Hitchings RA, Rice NSC. The long-term effects of 5-fluorouracil and sodium butyrate on human Tenon's fibroblasts. Invest Ophthalmol Vis Sci 1992;33:2043-52.

24 Khaw PT, Doyle JW, Sherwood MB, Smith MF, McGorray $\mathrm{S}$. Effects of intraoperative 5-fluorouracil or mitomycin C on glaucoma filtration surgery in the rabbit. Ophthalmology 1993;100:367-72.

25 Migdal C, Gregory W, Hitchings RA. Long term functional outcome after early surgery compared with laser and medioutcome after early surgery compared with laser and medi-
cine in open angle glaucoma. Ophthalmology 1994;101: cine in $1651-7$.

26 Thommy CP, Bhar IS. Trabeculectomy in Nigerian patients with open angle glaucoma. Br F Ophthalmol 1979;63:63642 .

27 Wilson R. Posterior lip sclerectomy vs trabeculectomy in West Indian blacks. Arch Ophthalmol 1989;107:1604-8.

28 Mermoud A, Salmon JF, Murray A. Trabeculectomy with mitomycin C for refractory glaucoma in blacks. $\mathrm{Am} \mathcal{f} \mathrm{Oph}$ thalmol 1993;116:72-8. 